\title{
Changing Behavior for Energy Saving and Health Indoor Best Practices for Public Administration and School Study Case
}

\author{
Patrizia Aversa ${ }^{1}$ and Anna Amato ${ }^{2 *}$ \\ ${ }^{1}$ Department for Sustainability, Italian National Agency for new Technologies, Italy \\ ${ }^{2}$ Energy Efficiency Department, Rome Casaccia Research Centre, Italy
}

Submission: March 27, 2019; Published: April 04, 2019

*Corresponding author: Anna Amato, CR ENEA Casaccia, via Anguillarese 301, Santa Maria di Galeria, Italy

\begin{abstract}
ENEA, the Italian Agency for new technologies, energy and sustainable economic development, promotes training and information campaigns for the dissemination of energy efficiency culture. The Public Administration plays a key role for the energy efficiency in Italy, planning energy policies concerning energy efficiency and representing one of the most energy consumers. Among public buildings, in particular, schools are crucial place with a symbolic significance. Energy renovation is not the only urgent need for the school buildings, indoor air quality in schools has received particular attention in recent years, as the large proportion of the time spent at schools. Unconventional information and training campaigns can lead to changing behaviour aiming at improving both energy saving and health indoor
\end{abstract}

Keywords: Energy efficiency, Schools, Public buildings, changing behaviour, sustainability, health indoor

\section{Introduction}

Energy efficiency is one of the five pillars of the Energy Union, and it is at the top of the political agenda in all the European countries for the global clean energy transition. The building sector is the largest energy consumer in Europe, absorbing $40 \%$ of final energy. About $75 \%$ of buildings are energy inefficient and, depending on the Member State, only $0.4-1.2 \%$ of the stock is renovated each year. The Public Administration plays a key role for the energy efficiency in Italy, planning energy policies concerning energy efficiency and representing one of the most energy consumers. According to the Energy Efficiency Directive[1], the European Commission recognizes the "exemplary role of public bodies' buildings", moreover, the new EU directive on energy performance of buildings 2 recognizes the relevance of the indoor air quality, and based on the guidelines of the World Health Organization, already from 2009, concerning indoor air quality, better performing buildings should provide higher comfort levels and wellbeing for their occupants and improve health [2]. Furthermore, Member States should support energy performance upgrades of existing buildings that contribute to achieving a healthy indoor environment, including through the removal of asbestos and other harmful substances.

ENEA, the Italian Agency for new technologies, energy and sustainable economic development, in addition to technical and scientific support for the country, promotes training and informa tion campaigns for the dissemination of energy efficiency culture. ENEA is the coordinator of a national project ES-PA "Energy and sustainability for Public Administration" to support the Regions and Municipalities offering products and services for planning and implementing policies in energy efficiency in buildings, circular economy, RES, smart grids [3]. School buildings have a major social responsibility. Raising awareness and involving school communities (students, teachers and families) can lead to energy saving in the whole building sector [4].

In the framework of EFFEDIL project, ENEA started to evaluate a monitoring strategy of the indoor air quality in a low secondary school in the South of Italy, where an energy retrofitting programme was undertaken. Among public buildings, schools are crucial place with a symbolic significance. Our children and young people spend years and the most part of the day inside these building, being involved in a one of the most important activities of their life [5]. Certainly, energy renovation is not the only urgent need for the school buildings, indoor air quality in schools has received particular attention in recent years, as the large proportion of the time spent at schools [6]. Scientific evidence, by monitoring public infrastructures, especially schools and students' facilities, in fact, has shown that the "sick building syndrome" can affect pathologies, such as allergies and headaches, as claimed by students. For this reason, the air quality of school environment, since Italian 


\section{Civil Engineering Research Journal}

school population is estimated to consist of 9.726.977 units including students and teachers, and administrative staff, is a significant element to be considered.

Indoor air pollution in schools is a combined effect and often depends on the level of environmental ventilation. The internal air within schools is often of poor quality. Schools are often poorly ventilated (as demonstrated by elevated $\mathrm{CO}_{2}$ levels) and several pollutants have been found in classrooms, such as bacteria, moulds, VOCs and PM. Associations have been reported among the concentrations of pollutants and the onset of health problems in schoolchildren, mainly respiratory/allergic symptoms and diseases [7]. The study case, which was conducted with the scope to set up a methodology for comfort evaluation and the indoor air quality, started with an experimental campaign in situ, by means of a sensor network specifically for the measurement of temperature, humidity, $\mathrm{CO} 2$, NOx, CO, VOCs.

However, the innovative idea was based on the active students involvement in the experimental phase, in a perspective of citizen science and Responsible Research and Innovation, aiming at the education of students, who become aware and able to disseminate the best practices to adopt concerning the energy policies, aiming at waste reduction and taking more advantages as possible about the health issue. The first phase was undertaken trough active information/training channel.

Later through a sensor network that is available in the market, micro-climatic parameters were monitored, together with temperature, humidity and $\mathrm{CO} 2$, which are often factors declining attention and learning in the classroom [8]. Through the training path on specific topics and by compiling daily tracking records, the reported information was used to synchronize all the data recorded through the sensor network. The indoor air pollution in the schools is a combined effect by indoor and outdoor physical, chemical and biological factors, and it is dependent also on environmental ventilation level. It results, for example, that $\mathrm{CO}_{2}$ levels are higher than 2000/3000ppmm, presence is recorded of VOC, $\mathrm{PM}$ and mildews, due to the materials used for the retrofitting, a scarce maintenance, the use of cleansers that are not always adequate for the surfaces to disinfect, also detected because of a not adequate ventilation [9]. The initial evaluations show as, for example, about the $\mathrm{CO}_{2}$ values are so strongly linked to some specific activities in the classroom and dependent on right air exchanges [10]. The study has shown that an aware management of the ventilation during all the seasons can maintain the $\mathrm{CO}_{2}$ values below $1000 \mathrm{ppm}$, so as reported in the picture below (Figure 1).

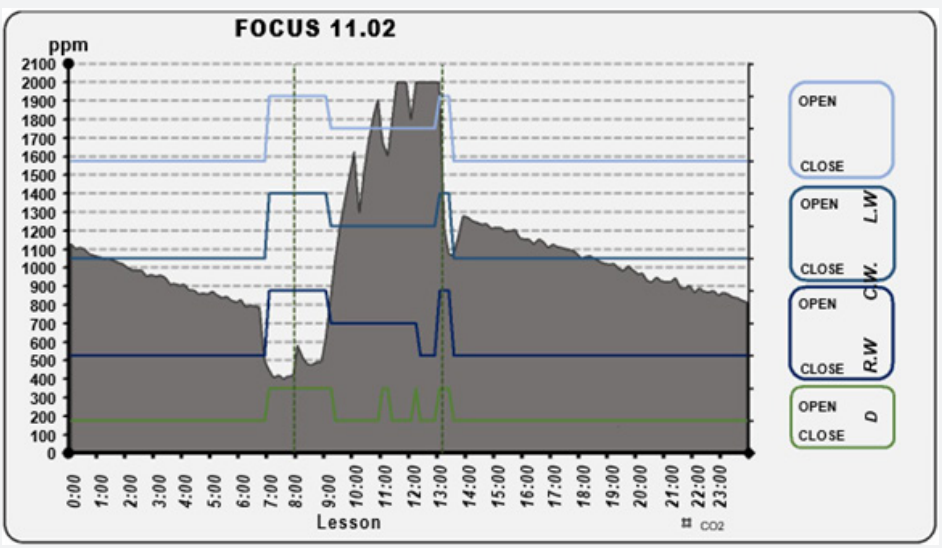

Figure 1: Trend in the classroom with students and natural ventilation $\mathrm{CO}_{2}-\mathrm{STUDENT}$-Window; L.W Left Window; R.W; C.W; Door.

The same trend was observed also for the other microclimatic factors such as Temperature and Humidity [11]. Other indicators of the indoor air quality were monitored in a preliminary way, such as $\mathrm{CO}$ and NOx. The first results show that these are present, but in small amount and much below the limit indicated by the World Health Organization, thanks to the scarce vehicular traffic close to school. Further indicators of indoor air quality are under evaluation. The preliminary results obtained in this data acquisition campaign allowed us to represent the health conditions of the investigated environment, moreover, to compare it with the wellness perceived by the students and in such a way the awareness raising contributed to make the quality and purity of the environment [12].

Currently, a large promotion to encourage the refurbishment of the schools is carried out, in order to make deep renovation and upgrade of the building stock towards nearly zero energy build- ings (NZEB) (Figure 2). Financial schemes and incentives were set up to support the production of thermal energy from renewables, as well as small-scale interventions of energy efficiency to give an important contribution in reducing the use of fossil fuels and in increasing efficiency through the use of energy resources in sectors that result to be critical from the viewpoint of energy consumption. According to the Clean Energy Package, energy efficiency also has a positive impact on health, and the related costs: modern and efficient heating installations burn less fossil fuel and emit fewer air pollutants, thus improving air quality and reducing greenhouse gas emissions. Adequately heated and ventilated dwellings alleviate negative health impacts caused by dampness, particularly amongst vulnerable groups such as children and the elderly and those with pre-existing illnesses.

In line with the European Environment Agency's documents, the Italian Ministry of Health has highlighted a relevant problem 


\section{Civil Engineering Research Journal}

in public health related to the indoor air quality in the building, which should respond even more to the bounding requirements in order to reach the goals through the energy saving within the 2050 with the intermediate steps. The Italian Ministry of Economic Development assigned a specific role to information and training as fundamental driver to create, reinforce and develop the attention towards energy saving and energy efficiency. Article 13 of Legislative Decree 102/2014, indeed, envisaged a specific Three-Year Training and Information Program which is coordinated by ENEA involving different actors as Regions, consumer associations, and associations of ESCos and energy services companies [13]. The program foresees TV and radio campaign, digital market action, a lot of different initiative for different targets, including students of any age and grade, the energy efficiency month initiative, etc.

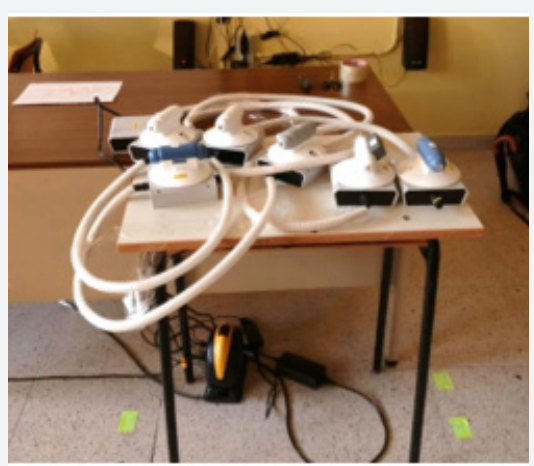

Figure 2: Nearly zero energy buildings.

A. The Programme consists of three phases

a. Phase 1-Start up (first year): massive information/communication activities on energy saving and energy efficiency topics, to ensure initial basic knowledge, through the national campaign "Italia in classe A" ("Italy in A class").

b. Phase 2-Tailored targets (second year): central phase of the Programme, maximizing information coverage and starting the tailored actions.

c. Phase 3 -Monitoring and consolidation (third year): consolidating the initiatives; dissemination of results and analysis of the communication impacts, with evaluation and control of achieved results.

In 2018 a "Roadshow in Energy Efficiency" was organized, itinerant and parallel events throughout the country, visiting ten medium-large Italian cities, disseminating the material from over 40 live linked events and with the possibility of reaching segmented targets, differentiating and personalizing the messages. In the workshop for Public Administration, together with lectures on the energy efficiency topics, also the indoor comfort subject was highlighted.

\section{Conclusion}

Energy efficiency measures requires the people engagement, new awareness and new skills. Interventions should include and consider the behavioral issues in all aspects of the energy, not only the technologies and materials that now are available. "Nudging" can be a useful instrument to make it easier for people to make a specific decisions and it can be usefully combined with education and training, to obtain long-term reorientation and introduce new habits. In the energy retrofitting interventions, several factors are taken into account, such as the construction materials, ventilation and measures adopted aiming at energy saving, and how this caused social and economic impacts. Communication with efficient instruments and experimental campaigns play a key role to prevent and mitigate indoor pollution in the daily environment. Skills and good practices behavior adoption can help to reach the energy goals of environmental policies, in order to reduce waste of resources and $\mathrm{CO}_{2}$ release, to promote monitoring actions and prevention in a medium/long term of indoor air quality. This could be realized also connecting innovation and science education strategies for responsible citizenship. The human dimension should be considered relevant since "technology alone does not guarantee low energy use in buildings" [14].

\section{References}

1. European Parliament and of the Council (2012) Directive 2012/27/EU of the European parliament and of the council of 25 October 2012 on energy efficiency, amending Directives 2009/125/EC and 2010/30/ EU and repealing Directives 2004/8/EC and 2006/32/EC

2. European Parliament and of the Council (2018) directive 2018/844/ EU of the European parliament and of the council of 30 May 2018 amending Directive 2010/31/EU on the energy performance of buildings and Directive 2012/27/EU on energy efficiency.

3. ENEA (2018-2021) Laboratori di Ricerca di Ispra.

4. DellaValle N, Bisello A, Balest J (2018) In search of behavioural and social levers for effective social housing retrofit programs.

5. (2016) Efficient Energy building Innovative solutions funded by Italian Ministry of Education and Research.

6. Lizana J, Serrano-Jimenez A, Ortiz C, Becerra JA, Chacartegui R (2018) Energy assessment method towards low-carbon energy schools. Energy 159: 310-326.

7. Jovanovic M, Vucicevic B, Turanjanin V, Zivkovic M, Spasojevic V (2014) Investigation of indoor and outdoor air quality of the classrooms at a school in Serbia.

8. Mendell MJ, Heath GA (2015) Do indoor pollutants and thermal conditions in schools influence student performance? A critical review of the literature 15: 27-32.

9. Madureira I, Paciencia C, Pereira JP, Teixeira E, Fernandes O (2016) Indoor air quality in Portuguese schools: levels and sources of pollutants. Indore air 26(4): 526-537.

10. Aversa P, Settimo G, Gorgoglione M, Bucci E, Giorgio P, et al. (2018) Advantages of continuous monitoring of indoor air quality in a school after energy efficiency improvement and redevelopment: a case study.

11. Aversa P, Bucci E, Gorgoglione M, Luprano VAM, Disi A (2000) Comfort Indoor: prevenzione e riduzione del rischio attraverso la gestione consapevole.

12. Avers P, Camporeale G, Pfister V, Luprano V (2011) Messa a punto di una metodologia di un setup sperimentale per la valutazione del comfort e qualità dell'aria negli ambienti indoor scolastici soggetti a riqualificazione energetica.

13. www.italiainclassea.enea.it

14. D'Oca S, Hong T, Langevin J (2017) The human dimensions of energy use in buildings: a review. 


\section{Civil Engineering Research Journal}

(C) This work is licensed under Creative

DOI: 10.19080/CERJ.2019.07.555726

Your next submission with Juniper Publishers will reach you the below assets

- Quality Editorial service

- Swift Peer Review

- Reprints availability

- E-prints Service

- Manuscript Podcast for convenient understanding

- Global attainment for your research

- Manuscript accessibility in different formats

( Pdf, E-pub, Full Text, Audio)

- Unceasing customer service

Track the below URL for one-step submission https://juniperpublishers.com/online-submission.php 